\title{
Do observations on surface coverage- reactivity correlations always describe the true catalytic process? A case study on ceria
}

Ramzi Farra, ${ }^{\mathrm{a}}$ Maik Eichelbaum, ${ }^{\mathrm{a}}$ Robert Schlögl, ${ }^{\mathrm{a}}$ László Szentmiklósi, ${ }^{\mathrm{b}}$ Timm Schmidt, ${ }^{\mathrm{c}}$ Amol P. Amrute, ${ }^{\mathrm{d}}$ Cecilia Mondelli, ${ }^{\mathrm{d}}$ Javier Pérez-Ramírez, ${ }^{\mathrm{d}}$ Detre Teschner ${ }^{\mathrm{a}, \mathrm{b}^{*}}$

${ }^{a}$ Fritz-Haber-Institut der Max-Planck Gesellschaft, Faradayweg 4-6, D-14195 Berlin,

\section{Germany}

${ }^{\mathrm{b}}$ Centre for Energy Research, Hungarian Academy of Sciences, Budapest, H-1525, Hungary

${ }^{\mathrm{c}}$ Bayer MaterialScience AG, PUR-PTI-PRI, Chempark B598, D-41538 Dormagen, Germany

${ }^{\mathrm{d}}$ Institute for Chemical and Bioengineering, Department of Chemical and Applied

Biosciences, ETH Zurich, Wolfgang-Pauli-Strasse 10, CH-8093 Zurich, Switzerland

\section{Email: teschner@,fhi-berlin.mpg.de}

Tel: +493084135408

Fax: +493084134676 


\begin{abstract}
In situ (operando) investigations aim at establishing structure-function and/or coverage-reactivity correlations. Herein, we investigated the $\mathrm{HCl}$ oxidation reaction $(4 \mathrm{HCl}+$ $\mathrm{O}_{2} \rightarrow 2 \mathrm{Cl}_{2}+2 \mathrm{H}_{2} \mathrm{O}$ ) over ceria. In spite of its remarkable performance, under low oxygen over-stoichiometry this oxide is prone to a certain extent to subsurface/bulk chlorination, which leads to deactivation. In situ Prompt Gamma Activation Analysis (PGAA) studies evidenced that the chlorination rate is independent of the pre-chlorination degree but increases at lower oxygen over-stoichiometry, while dechlorination is effective in oxygen-rich feeds and its rate is higher for a more extensively pre-chlorinated ceria. Even bulk $\mathrm{CeCl}_{3}$ could be transformed into $\mathrm{CeO}_{2}$ under oxygen excess. Electron Paramagnetic Resonance experiments strongly suggested that oxygen activation is inhibited by a high surface chlorination degree. The coverages of most abundant surface intermediates, $\mathrm{OH}$ and $\mathrm{Cl}$, were monitored by in situ infrared spectroscopy and PGAA under various conditions. Higher temperature and $p\left(\mathrm{O}_{2}\right)$ led to enhanced $\mathrm{OH}$ coverage, reduced $\mathrm{Cl}$ coverage, and increasing reactivity. Variation of $p(\mathrm{HCl})$ gave rise to opposite correlations, while raising $p\left(\mathrm{Cl}_{2}\right)$ did not induce any measurable increase in the $\mathrm{Cl}$ coverage despite the strong inhibition of the reaction rate. The results indicate that only a small fraction of surface sites are actively involved in the reaction and most of the surface species probed in the in situ observation are spectator. Therefore, when performing in situ steady-state experiments, a large set of variables should be considered to obtain accurate conclusions.
\end{abstract}

Keywords: $\mathrm{CeO}_{2}$, in situ FTIR, in situ PGAA, EPR, $\mathrm{HCl}$ oxidation, surface coverage 


\section{Introduction}

Heterogeneous catalysis is a kinetically-driven phenomenon, and the reaction rate is proportional to the coverage of at least one reactant, or surface species or by the number of free sites. Nevertheless, the dependence can be fairly complex, and the extent of sites occupied by blocking species crucially affects the catalyst's efficiency. The coverage of reactants, intermediates, and products strongly depends on their heat of adsorption at the relevant active surface site and on the barriers related to the formation and elimination of these surface species. The quantitative information on the surface coverage plays an important role in identifying reaction mechanisms, designing alternative catalysts, or validating purely computational approaches. Thus, the knowledge of the surface coverage at meaningful catalytic turnover is critical and has always been the motivation of extensive experimental efforts. ${ }^{1,2,3}$ Unfortunately, only a very few number of experimental techniques are capable of deriving such information, the most important ones being the various forms of vibrational spectroscopies. In this manuscript we will experimentally assess the coverage of surface species under catalytic turnover and correlate these with the reactivity. The catalytic $\mathrm{HCl}$ oxidation (Deacon reaction) over bulk ceria will serve as our example.

The heterogeneously catalyzed $\mathrm{HCl}$ oxidation is a sustainable route to manufacture chlorine, and the current technology is based on $\mathrm{RuO}_{2}$ catalysts. ${ }^{4,5,6,7,8} \mathrm{CeO}_{2}$ was recently identified as a cheaper potential alternative active phase in view of its remarkable stability, though it requires higher operating temperatures. ${ }^{9}$ As revealed by XRD and XPS analyses, when using an appropriate over-stoichiometry of oxygen in the feed gas $\left(\mathrm{O}_{2}: \mathrm{HCl}>0.75\right)$ the bulk of ceria was unaffected and only the surface got chlorinated under reaction condition. The mechanism of $\mathrm{HCl}$ oxidation over $\mathrm{CeO}_{2}$ was suggested to involve the following elementary steps: (i) hydrogen abstraction from $\mathrm{HCl}$ by basic surface $\mathrm{O}$ atoms to form hydroxyl groups leaving chlorine atoms on the surface, (ii) reaction of the hydroxyl groups 
with new incoming $\mathrm{HCl}$ molecules and/or hydroxyl group recombination on the surface to form water, (iii) water desorption, (iv) re-oxidation of the surface via dissociative adsorption of $\mathrm{O}_{2}$, and (v) recombination of chlorine atoms evolving in the gas phase as $\mathrm{Cl}_{2} .{ }^{9}$ Several of these steps rely on the existence of anionic oxygen vacancies that accommodate dissociated reactants. Based on the above mechanism, adsorbed $\mathrm{Cl}, \mathrm{OH}$, and $\mathrm{H}_{2} \mathrm{O}$ are the major species populating the surface. These may occupy coordinatively unsaturated cationic sites or lattice O sites by replacement.

This manuscript attempts to address two novel aspects of the Deacon reaction over $\mathrm{CeO}_{2}$. First, we investigate the chlorine uptake under reaction conditions and follow the kinetics of the dynamic chlorination and dechlorination process depending on the oxygen over-stoichiometry of the feed mixture. Second, we examine the coverage of $\mathrm{Cl}$ and $\mathrm{OH}$ under various reaction conditions and relate them with reactivity. We show how convincing coverage-rate correlations break down when product inhibition is included in the experiments, and conclude that the observed correlations are associated with the main part of the surface bearing little relevance for the reactivity.

\section{Experimental}

\section{Catalysts}

$\mathrm{CeCl}_{3}$ (Alfa Aesar, ultra dry, 99.9\%) was used as received. $\mathrm{CeO}_{2}$ (Aldrich, nanopowder, 544841) was calcined in static air at $1173 \mathrm{~K}$ for $5 \mathrm{~h}$ prior to use. This sample is referred to as $\mathrm{CeO}_{2}-\mathrm{A}$. $\mathrm{CeO}_{2}-\mathrm{R}$ was synthesized by thermal decomposition of cerium(III) nitrate hexahydrate (Aldrich, $99.99 \%)$ in air by ramping to $1173 \mathrm{~K}\left(2 \mathrm{~K} \mathrm{~min}^{-1}\right)$ and holding for $3 \mathrm{~h} . \mathrm{CeO}_{2}-\mathrm{A}$ and $\mathrm{CeO}_{2}-\mathrm{R}$ possessed BET surface areas of 21 and $5 \mathrm{~m}^{2} \mathrm{~g}^{-1}$, respectively, after catalytic testing. For the EPR experiments, $\mathrm{CeO}_{2}-\mathrm{A}$ was treated in $\mathrm{O}_{2}: \mathrm{HCl}=0.75$ at 703 $\mathrm{K}$ for $3 \mathrm{~h}$. This sample is denoted as $\mathrm{CeO}_{2}-\mathrm{D}$. 


\section{Basic characterization}

Powder X-ray diffraction (XRD) was measured in a PANanalytical X'Pert PRO-MPD diffractometer. Data were recorded in the $10-70^{\circ} 2 \theta$ range with an angular step size of $0.017^{\circ}$ and a counting time of $0.26 \mathrm{~s}$ per step. $\mathrm{N}_{2}$ sorption at $77 \mathrm{~K}$ was measured in a Quantachrome Quadrasorb-SI gas adsorption analyzer. The samples were degassed in vacuum at $473 \mathrm{~K}$ for $12 \mathrm{~h}$ prior to the measurement.

In situ Prompt Gamma Activation Analysis (PGAA)

In situ $\mathrm{PGAA}^{10}$ was utilized to measure the $\mathrm{Cl}$ uptake of ceria during $\mathrm{HCl}$ oxidation. The technique is based on the detection of element-specific gamma rays emitted upon the capture of neutrons by the nucleus. The investigated volume, in our case a tubular microreactor (catalyst bed volume $\sim 0.3 \mathrm{~cm}^{3}$ ), was probed and the amounts of $\mathrm{Cl}$ and $\mathrm{Ce}$ were quantified. PGAA was carried out under atmospheric pressure condition at the cold neutron beam of the Budapest Neutron Centre. A Compton-suppressed high-purity germanium crystal was used to detect the prompt gamma photons. Molar ratios $(\mathrm{Cl}: \mathrm{Ce})$ were determined from the characteristic peak areas corrected by the detector efficiency and the nuclear data of the observed elements. The gas-phase $\mathrm{Cl}$ signal $\left(\mathrm{HCl}, \mathrm{Cl}_{2}\right)$ was subtracted, thus, all $\mathrm{Cl}$ :Ce ratios reported here correspond only to the catalyst itself. The quartz reactor (i.d. $=8 \mathrm{~mm}$ ) was placed into the neutron beam and surrounded by a specially designed oven having openings for the incoming and outgoing neutrons and for the emitted gamma rays towards the detector. These openings were covered by thin aluminum foils to minimize heat losses. Two $\mathrm{CeO}_{2}$ materials $\left(\mathrm{CeO}_{2}-\mathrm{A}, \mathrm{CeO}_{2}-\mathrm{R}\right)$ were investigated. As both revealed the same trends, only the more detailed investigation on $\mathrm{CeO}_{2}-\mathrm{R}$ is presented in the PGAA section, while results on $\mathrm{CeO}_{2}-\mathrm{A}$ are collected in the Electronic Supplementary Information (ESI). $0.8 \mathrm{~g}$ of $\mathrm{CeO}_{2}-\mathrm{R}$ (sieve fraction $0.1-0.32 \mathrm{~mm}$ ) was loaded into the reactor. The reaction feed, at a constant total flow of $166.6 \mathrm{~cm}^{3} \mathrm{STP} \mathrm{min}^{-1}$, was supplied by mass flow controllers, and employed $\mathrm{HCl}$ 
(4.5), $\mathrm{O}_{2}(5.0) \mathrm{N}_{2}$ (5.0) and $\mathrm{Cl}_{2}$ (4.0). Various feed compositions, $p\left(\mathrm{O}_{2}\right), p(\mathrm{HCl})$ and $p\left(\mathrm{Cl}_{2}\right)$, and reaction temperature were investigated. Details are provided at the appropriate sections. The $\mathrm{Cl}_{2}$ production was monitored by iodometric titration. The percentage of $\mathrm{HCl}$ conversion was determined as $X_{\mathrm{HCl}}=\left(2 \times\right.$ mole $\mathrm{Cl}_{2}$ at the reactor outlet/mole $\mathrm{HCl}$ at the reactor inlet $) \times 100$. Further details to PGAA and representative spectra are provided in the ESI.

\section{Catalytic evaluation}

The gas-phase oxidation of hydrogen chloride was studied at ambient pressure in a set up described elsewhere. ${ }^{11}$ The catalyst (sieve fraction $=0.4-0.6 \mathrm{~mm}$ ) was loaded in the tubular reactor ( $8 \mathrm{~mm}$ i.d.) and pre-treated in $\mathrm{N}_{2}$ at $703 \mathrm{~K}$ for $30 \mathrm{~min}$. Thereafter, the reaction gases were introduced at a total flow of $166 \mathrm{~cm}^{3} \mathrm{STP} \mathrm{min}^{-1} . \mathrm{CeCl}_{3}$ was tested at $703 \mathrm{~K}$ or $723 \mathrm{~K}$, $\mathrm{O}_{2}: \mathrm{HCl}=2,4$, or 9 , and a catalyst weight of $0.5 \mathrm{~g}$. Separated $5 \mathrm{~h}$ tests were carried out with fresh loads of $\mathrm{CeCl}_{3}$ for each different $\mathrm{O}_{2}: \mathrm{HCl}$ ratio and temperature. Used samples were collected for post mortem characterization after rapidly cooling down the reactor to room temperature in a flow of $\mathrm{N}_{2}$. Activity data were collected for $\mathrm{CeO}_{2}-\mathrm{A}$ after $1 \mathrm{~h}$ on stream under all conditions applied to $\mathrm{CeCl}_{3}$ to serve as reference. The influence of $\mathrm{Cl}_{2}$ co-feeding on the rate of $\mathrm{HCl}$ oxidation over $\mathrm{CeO}_{2}$-A was studied by introducing fixed amounts $(2,3,4$, and $5 \mathrm{~cm}^{3} \mathrm{STP} \mathrm{min}^{-1}$ ) of $\mathrm{Cl}_{2}$ to the inlet feed at $703 \mathrm{~K}$ and $\mathrm{O}_{2}: \mathrm{HCl}=9$ (notice $\mathrm{HCl}$ flow is 16.6 $\mathrm{cm}^{3}$ STP $\mathrm{min}^{-1}$ ), over $0.25 \mathrm{~g}$ of catalyst. Data was taken after $1.5 \mathrm{~h}$ on stream under each condition. $\mathrm{Cl}_{2}$ quantification and calculation of the $\mathrm{HCl}$ conversion were performed as described in the above section.

\section{In situ Fourier Transform Infrared Spectroscopy (FTIR)}

A specially designed home-made cell was used to investigate Deacon catalysts under reaction conditions. Further details about the cell were reported elsewhere. ${ }^{12}$ For in situ FTIR experiments, $42 \mathrm{mg} \mathrm{CeO}_{2}-\mathrm{A}$ was pressed into a self-supporting disc $\left(31.8 \mathrm{mg} \mathrm{cm}^{-2}\right)$. The sample was placed in the sample holder which serves as an internal furnace as well. The pellet 
was pre-treated in situ by heating it in synthetic air up to $723 \mathrm{~K}\left(10 \mathrm{~K} \mathrm{~min}^{-1}\right)$. Spectra were recorded with a Varian-670 FTIR spectrometer (resolution $=4 \mathrm{~cm}^{-1}$ ). In most cases, 512 scans were averaged to achieve a satisfactory signal-to-noise ratio. Mass flow controllers were used to supply the reaction feed (total flow $=100 \mathrm{~cm}^{3} \mathrm{STP} \mathrm{min}^{-1}$ ). The effect of $p\left(\mathrm{O}_{2}\right), p(\mathrm{HCl})$, and temperature were investigated under Deacon conditions. In the $\mathrm{O}_{2}$ partial pressure dependent series, the $\mathrm{HCl}$ flow was kept constant at $10 \mathrm{~cm}^{3} \mathrm{STP} \min ^{-1}$ and $p\left(\mathrm{O}_{2}\right)$ was varied to give the following feed composition sequence $\mathrm{O}_{2}: \mathrm{HCl}: \mathrm{N}_{2}=9: 1: 0,4: 1: 5,2: 1: 7,1: 1: 8$ and 0.5:1:8.5. During the measurement of the $\mathrm{HCl}$ partial pressure dependence, the $\mathrm{O}_{2}$ flow was kept constant at $20 \mathrm{~cm}^{3} \mathrm{STP} \mathrm{min}^{-1}$ and $\mathrm{HCl}$ flow was varied as follows: $10,6,3$ and $1 \mathrm{~cm}^{3} \mathrm{STP}$ $\min ^{-1}$. In the partial pressure variation experiments, the temperature was kept at $703 \mathrm{~K}$. The temperature dependence was investigated by reducing the temperature stepwise, $20 \mathrm{~K}$ per step, between 703 and $623 \mathrm{~K}$ using a feed composition of $\mathrm{O}_{2}: \mathrm{HCl}_{2} \mathrm{~N}_{2}=9: 1: 0$.

\section{Electron Paramagnetic Resonance (EPR) experiments}

The X-band EPR experiments were performed in vacuum $\left(1 \cdot 10^{-4}-8 \cdot 10^{-5}\right.$ mbar $)$ at $77 \mathrm{~K}$ on a Bruker ESP 300E spectrometer equipped with the microwave bridge Bruker ER 042 MRH E. A Bruker ER 4116DM resonator operating in the TE 102 mode $(v \approx 9.5 \mathrm{GHz})$ was used. All spectra were recorded with a modulation frequency of $100 \mathrm{kHz}$ and microwave power of $2 \mathrm{~mW}$ with modulation amplitude of $1 \mathrm{G}$. Measurements were performed with $70 \mathrm{mg}$ of non-chlorinated $\left(\mathrm{CeO}_{2}-\mathrm{A}\right)$ and $140 \mathrm{mg}$ of chlorinated $\left(\mathrm{CeO}_{2}-\mathrm{D}\right)$ samples in a quartz tube of $3 \mathrm{~mm}$ inner diameter. EPR spectra of both samples were collected after the following pretreatment procedure. After degassing, the sample was heated up $\left(10 \mathrm{~K} \mathrm{~min}^{-1}\right)$ in vacuum to the desired temperature $(523,623$ and $723 \mathrm{~K})$. The temperature was kept constant for $20 \mathrm{~min}$, and then the sample was cooled down to room temperature. $\mathrm{O}_{2}$ adsorption was carried out at RT by dosing 1 mbar $\mathrm{O}_{2}$ during $5 \mathrm{~min}$. Afterwards, the cell was outgassed and the sample cooled down to $77 \mathrm{~K}$ for collecting EPR spectra. This procedure was repeated for every treatment 
temperature. Computer simulations of EPR line-shapes with Bruker Simfonia software were used to calculate spectral parameters. All spectra were normalized by the sample masses for semi-quantitative comparison of the signal double integrals after different treatments.

\section{Results}

\section{Kinetics of chlorination and dechlorination}

Previous $\mathrm{HCl}$ oxidation experiments over $\mathrm{CeO}_{2}$ assessed the role of feed oxygen concentration on the stability of the catalyst. ${ }^{9}$ It was found that no rapid deactivation occurred above a feed $\mathrm{O}_{2}: \mathrm{HCl}$ ratio of 0.75 . Post-reaction XRD measurements identified $\mathrm{CeCl}_{3} \cdot 6 \mathrm{H}_{2} \mathrm{O}$ in the samples undergoing deactivation, suggesting that bulk chlorination and the corresponding phase transition induced activity loss. Furthermore, in situ activity restoration was possible applying high $\mathrm{O}_{2}$ feed over-stoichiometry. Herein, using in situ PGAA, we evaluated the kinetics of chlorination/dechlorination of $\mathrm{CeO}_{2}-\mathrm{R}$ under $\mathrm{HCl}$ oxidation conditions. Since PGAA probes the whole catalyst volume, the bulk of ceria is included in the experimentally determined $\mathrm{Cl}$ :Ce ratios. The BET surface area of $\mathrm{CeO}_{2}-\mathrm{R}$ is only $5 \mathrm{~m}^{2} \mathrm{~g}^{-1}$ (the average particle radius is $\sim 80 \mathrm{~nm}$ ), and, hence, the $\mathrm{Cl}$ :Ce ratios are small. Later we will show that $\mathrm{Cl}$ occupation limited to the surface of $\mathrm{CeO}_{2}-\mathrm{R}$ gives rise to a $\mathrm{Cl}$ :Ce ratio of $\sim 0.01$ and higher numbers necessarily imply subsurface and bulk $\mathrm{Cl}$ contributions. It should be mentioned that by the term 'surface chlorination', we do not differentiate cus Ce occupation or surface lattice $\mathrm{O}$ replacement.

Three series of experiments were performed (Figure 1A). First, a reaction feed of $\mathrm{O}_{2}: \mathrm{HCl}=1: 1$ was set and the activity together with the $\mathrm{Cl}: \mathrm{Ce}$ ratio was followed over time. Then, the oxygen content was increased stepwise leading to feeds with a $\mathrm{O}_{2}: \mathrm{HCl}$ ratio of $2: 1$, 4:1, and 9:1. In the second series, directly after the first, we started with an $\mathrm{O}_{2}: \mathrm{HCl}$ ratio of 0.5:1 and stepwise increased the oxygen content up to a ratio of $9: 1$. In the third series, 
directly after the second, a stoichiometric $(0.25: 1)$ feed was applied and the oxygen content was again raised stepwise up to the ratio of 9:1. Figure $1 \mathrm{~B}$ compiles the evolution of chlorine uptake and its effect on the reactivity in the three series. The first data point (1:1), taken after equilibration for $1 \mathrm{~h}$, corresponds to $\sim 0.02 \mathrm{Cl}$ :Ce and $4 \% \mathrm{HCl}$ conversion level. The sample continuously adsorbed chlorine, and the $\mathrm{Cl}: \mathrm{Ce}$ increased up to 0.067 over the $6 \mathrm{~h}$ of measurement without any indication of the $\mathrm{Cl}$ uptake to cease. Concomitantly, the sample lost approximately $15 \%$ of its initial activity. Increasing the feed oxygen content gave rise to activity increase in line with the positive, approx. +0.5 , formal order of $p\left(\mathrm{O}_{2}\right) .{ }^{9}$ No further rise of $\mathrm{Cl}$ :Ce was observed in the first set, and dechlorination was negligible in the feed of 9:1. In the second series of the experiment, strong chlorination was again evidenced at $0.5: 1$ and 1:1 feed ratios, and chlorination stopped at 2:1. Note, among the three series, all repeated conditions resulting in a significantly higher $\mathrm{Cl}$ :Ce ratio gave rise to lower $\mathrm{HCl}$ conversion. This time, with more than doubled $\mathrm{Cl}$ content, the 9:1 feed was capable to induce dechlorination with simultaneous activity recovery. Essentially similar observations could be made for the third measurement series, with the difference that the 9:1 feed enabled strong dechlorination with significant activity recovery. Note that even if dechlorination was far from complete $(\mathrm{Cl}: \mathrm{Ce}=0.125)$, the conversion level was fully restored. In fact, it was slightly even higher than in the first two series. As the whole experiment took more than $32 \mathrm{~h}$, the sample at 9:1 feed worked essentially without deactivation, underlining the remarkable stability of the catalyst. Since mere surface $\mathrm{Cl}$ occupation leads to a $\mathrm{Cl}$ :Ce ratio of $\sim 0.01$, the sample under all these conditions contains much $\mathrm{Cl}$ below the surface. The results described suggest that (i) chlorination at low oxygen over-stoichiometry indeed gives rise to deactivation, but (ii) dechlorination at high oxygen over-stoichiometry can clean up the relevant surface sites without the necessity of removing all subsurface/bulk $\mathrm{Cl}$ from the material. Figure $1 \mathrm{C}$ depicts an example of the temporal evolution of $\mathrm{Cl}$ :Ce. The data 
illustrates that chlorination occurs continuously with a constant rate. When analyzing the chlorination rate at 1:1 feed composition as a function of the pre-chlorination degree in the three series, only little variation was found. Thus, the chlorination rate is not much affected by the pre-chlorination degree. However, despite the continuous chlorination, no further deactivation over time was observed at 1:1 feed in the second and third series. Comparing the chlorination rate as a function of the oxygen content in the feed (Figure 1D), we found that a lower oxygen content preferentially facilitates chlorination and that sustained chlorination is absent at $\mathrm{O}_{2}: \mathrm{HCl} \geq 2$. Dechlorination was not observed in the $4: 1$ feed, and, among the feed stoichiometries probed, only 9:1 was effective in this respect. As opposed to chlorination, dechlorination was strongly influenced by the pre-chlorination degree. Whereas almost no dechlorination was found in the first series, the estimated thickness change was -2.2 and -4.8 $\AA \mathrm{h}^{-1}$ in the second and third series, respectively.

As chlorinated $\mathrm{CeO}_{2}$ could be rapidly transformed back into pure $\mathrm{CeO}_{2}$ by applying a high oxygen excess, ${ }^{9}$ it was investigated whether rejuvenation of the oxide could be possible also starting with a pure chloride phase. Therefore, bulk $\mathrm{CeCl}_{3}$ was exposed to feeds of different $\mathrm{O}_{2}: \mathrm{HCl}$ ratio at $703 \mathrm{~K}$ and the used samples were analyzed by XRD (Figure 2). At $\mathrm{O}_{2}: \mathrm{HCl}=2$, the $\mathrm{HCl}$ conversion level was very low $(\sim 2 \%)$ throughout the $5 \mathrm{~h}$ test, and only traces of cerium(IV) oxide were detected in the sample after reaction. By using the same feed composition but a $20 \mathrm{~K}$ higher temperature, the initially low $\mathrm{HCl}$ conversion progressively increased, nearly reaching the level exhibited by our reference $\mathrm{CeO}_{2}-\mathrm{A}$ sample under identical reaction conditions $(\sim 22 \%)$. In this case, the original chloride phase almost fully transformed into $\mathrm{CeO}_{2}$. Using higher feed $\mathrm{O}_{2}: \mathrm{HCl}$ ratios (4 and 9) rapidly led to a $\mathrm{HCl}$ conversion level which even surpassed that expected for $\mathrm{CeO}_{2}$ under the same conditions. The used samples were pure ceria. These data indicates that the active $\mathrm{CeO}_{2}$ phase can be in situ generated from $\mathrm{CeCl}_{3}$ by action of gas-phase $\mathrm{O}_{2}$ and that the kinetics of its formation is faster for higher 
oxygen excess. The overshooting of the $\mathrm{HCl}$ conversion values for $\mathrm{CeCl}_{3}$ rejuvenated at $\mathrm{O}_{2}: \mathrm{HCl}=4$ and 9 compared to $\mathrm{CeO}_{2}$ can be partially rationalized considering that the decomposition of the chloride to produce the oxide releases $\mathrm{Cl}_{2}$. This process is fast and complete for these samples, while slower and only partial for $\mathrm{CeCl}_{3}$ exposed to lower $\mathrm{O}_{2}: \mathrm{HCl}$ ratios. Furthermore, as the surface area of these materials is 2-3 times larger than that of $\mathrm{CeO}_{2}$ used as reference (Table 1), they are supposed to contain a higher amount of active surface ensembles per gram of catalyst. The reaction rate per $\mathrm{m}^{2}$ of surface after $5 \mathrm{~h}$ on stream is in a similar range to that of pure ceria for all rejuvenated samples, indicating a high degree of recovery of the reactivity (Table 1). Comparing this rejuvenation experiment with the dechlorination study by PGAA, the low stability of $\mathrm{CeCl}_{3}$ under Deacon conditions can be clearly inferred. Subsurface $\mathrm{Cl}$ in $\mathrm{O}$ vacancy position within the oxide phase has a higher stability against dechlorination; nevertheless both dechlorination experiments revealed the same trends.

The two $\mathrm{CeO}_{2}$ samples $\left(\mathrm{CeO}_{2}-\mathrm{R}, \mathrm{CeO}_{2}-\mathrm{A}\right)$ investigated in this work exhibited similar intrinsic reactivity and chlorine uptake as measured by in situ PGAA. As we shall see in the next section, product $\mathrm{Cl}_{2}$ inhibits the reaction, and therefore linear activity scaling by the BET surface area is not given, nevertheless the similarity of the two $\mathrm{CeO}_{2}$ samples is still clear. Furthermore, the evolution of in situ $\mathrm{Cl}$ :Ce ratios derived as a function of reaction conditions were essentially identical, as described in the next section and shown in Figure ESI 1. Thus, the samples behave similarly in $\mathrm{HCl}$ oxidation.

\section{Surface coverage analysis}

Important mechanistic information may been obtained when combining different complementary in situ techniques ${ }^{13,14,15}$ able to follow the changes of different adsorbed species and intermediates on the surface of the catalyst at work. As we have seen in the chlorination section, in situ PGAA is well suited to quantify the chlorine uptake of ceria, and 
thus we can utilize the technique also to estimate the evolution of the $\mathrm{Cl}$ coverage as a function of the reaction conditions. One of the best complementary techniques to PGAA is in situ FTIR spectroscopy, affording to monitor the dynamic changes of the hydroxyl groups under reaction conditions. For the FTIR experiments, $\mathrm{CeO}_{2}$ was activated in situ using synthetic air at $703 \mathrm{~K}$ for $90 \mathrm{~min}$. After this pre-treatment, two main bands at 3700 and 3620 $\mathrm{cm}^{-1}$ were observed, which are assigned to mono- and doubly-coordinated hydroxyl groups, respectively. ${ }^{16}$ These two bands vanished when introducing a mixture of $\mathrm{O}_{2}: \mathrm{HCl}=9: 1$ at 703 $\mathrm{K}$, with the concomitant development of two signals, the main one falling at $3730 \mathrm{~cm}^{-1}$ and a shoulder located at $3676 \mathrm{~cm}^{-1} \cdot{ }^{12}$ Furthermore, a very broad band near $3500 \mathrm{~cm}^{-1}$, likely related to surface water, was also observed. Since the mono-coordinated band at $3730 \mathrm{~cm}^{-1}$ showed to quickly respond to changes in reactants concentrations and temperature, the integral area of this peak, obtained from fitting the absorbance spectra, was used to correlate the abundance of mono-coordinated $\mathrm{OH}$ groups with the catalyst reactivity under different reaction conditions. More details and spectra to the in situ FTIR experiments are published elsewhere. ${ }^{12}$

The effect of $p\left(\mathrm{O}_{2}\right)$ on the concentration of $\mathrm{OH}$ species, referenced to the one observed in a feed of $\mathrm{O}_{2}: \mathrm{HCl}=9: 1$, is illustrated in Figure 3A. The amount of $\mathrm{OH}$ groups decreased when reducing the $\mathrm{O}_{2}$ content in the feed, suggesting that sites to facilitate $\mathrm{HCl}$ adsorption need to be created by dissociative $\mathrm{O}_{2}$ adsorption. In the case of the $p(\mathrm{HCl})$ dependency (Figure 3B), the $\mathrm{OH}$ concentration was maximum at the lowest feed $\mathrm{HCl}$ concentration (1 vol.\%), and steadily decreased by increasing the feed $\mathrm{HCl}$ content. This apparently counterintuitive result will be discussed later with the corresponding surface $\mathrm{Cl}$ evolution. Further, the influence of the reaction temperature on the $\mathrm{OH}$ concentration was also studied. It appeared that the abundance of $\mathrm{OH}$ progressively diminished along with temperature from 703 to $623 \mathrm{~K}$ (Figure 3C). 
The correlation between reaction rate $\left(\mathrm{mol} \mathrm{g}^{-1} \mathrm{CeO} 2 \mathrm{~h}^{-1}\right)$ and the abundance of $\mathrm{OH}$ groups on the surface for the above variation of parameters is summarized in Figure 3D. Obviously, changes in temperature and $p\left(\mathrm{O}_{2}\right)$ determined the same trend, in the sense that the highest rate was achieved at the conditions (high temperature or oxygen-rich feed) that give rise to the highest $\mathrm{OH}$ coverage. This indicates that these two parameters may act in a similar fashion. In contrast, variation of $p(\mathrm{HCl})$ revealed an opposite behavior. In fact, the highest $\mathrm{Cl}_{2}$ productivity was achieved by using reaction conditions (high $p(\mathrm{HCl})$ feed) under which the lowest surface $\mathrm{OH}$ concentration is observed.

Figure 4 compiles the activity data versus the $\mathrm{Cl}$ uptake measured by in situ PGAA when varying $p\left(\mathrm{O}_{2}\right), T, p(\mathrm{HCl})$, and $p\left(\mathrm{Cl}_{2}\right)$. All these experimental series started with an oxidizing treatment in pure oxygen at $723 \mathrm{~K}$ for $2 \mathrm{~h}$. This enables to remove essentially most of the chlorine from the material. Pre-experiments indicated the effect of the studied variables on the $\mathrm{Cl}$ content, and thus all of these series were performed in such a way that the first measurement should induce the smallest $\mathrm{Cl}$ uptake and the last measurement the largest.

Figure 4A depicts the effect of $p\left(\mathrm{O}_{2}\right)$. The highest oxygen containing feed $\left(\mathrm{O}_{2}: \mathrm{HCl}=\right.$ 9:1) led to the highest reactivity and to the lowest $\mathrm{Cl}$ uptake. Decreasing the oxygen overstoichiometry lowered the reactivity and in parallel increased the $\mathrm{Cl}$ content. As shown in Figure 1B, a 1:1 feed led to a continuous increase of the chlorine content in the solid. This is seen here too, as the second measurement gave a clearly higher $\mathrm{Cl}: \mathrm{Ce}$ ratio. The effect was even stronger in the $0.5: 1$ feed, in agreement with Figure 1D. Therefore, by decreasing the partial pressure of $\mathrm{O}_{2}$, the $\mathrm{Cl}$ coverage increases slightly until the point where the chemical potential of surface $\mathrm{Cl}$ is high enough to induce its diffusion into the subsurface and later gives rise to a phase transition from the oxide to the chloride. Transition from purely surface to subsurface and bulk chlorination with this sample was in the $\mathrm{Cl}$ :Ce range of $\sim 0.01-0.012$. The effect of the temperature on the $\mathrm{OH}$ coverage was very similar to that of $p\left(\mathrm{O}_{2}\right)$. This is 
one-by-one transferable to the $\mathrm{Cl}$ coverage. High temperature results in higher reaction rate and concomitantly in a lower $\mathrm{Cl}$ content. As the $\mathrm{T}$ decreases, $\mathrm{Cl}$ :Ce slightly increases until at a certain temperature $(653 \mathrm{~K}$ in this particular case) subsurface population kicks in. The trends in $p\left(\mathrm{O}_{2}\right)$ and $T$ can be overlaid very well, and suggest that in these experiments the $\mathrm{Cl}$ coverage is a key (negative) parameter governing reactivity. This simple situation however changes for the influence of $p(\mathrm{HCl})$, as it can be deduced from Figure $4 \mathrm{C}$. In a very diluted $\mathrm{HCl}$-poor feed, the reactivity gets higher by increasing the inlet $\mathrm{HCl}$ concentration. This applies until a certain point, above which the rate drops by a further increase of $p(\mathrm{HCl}) .{ }^{9}$ Note that in this experiment (Figure 4C) we only monitored the increasing activity branch. Since the $\mathrm{O}_{2}: \mathrm{HCl}$ ratio in the $p\left(\mathrm{O}_{2}\right)$ series gave rise to decreasing $\mathrm{Cl}: \mathrm{Ce}, p(\mathrm{HCl})$ is expected to show an opposite behavior. This is indeed the case, as higher $p(\mathrm{HCl})$ increases the $\mathrm{Cl}$ coverage. Therefore, due to the concomitant activity increase, the $\mathrm{Cl}$ coverage cannot be regarded per se as the sole negative factor reducing reactivity. Looking back at the lower $\mathrm{OH}$ intensity in the infrared spectra with increasing $p(\mathrm{HCl})$, as higher $p(\mathrm{HCl})$ will build up a higher $\mathrm{Cl}$ coverage, the steady-state situation should plateau at a lower $\mathrm{OH}$ coverage, assuming that $\mathrm{OH}$ recombination and water evolution are more facile than $\mathrm{Cl}_{2}$ desorption. This likely explains the apparently counterintuitive trend in $\mathrm{OH}$ abundance. The situation gets even more complex when considering the effect of product co-feeding. Figure 4D shows the effect of various amounts of $\mathrm{Cl}_{2}$ introduced into a standard feed of $\mathrm{O}_{2}: \mathrm{HCl}=9: 1$ on the $\mathrm{Cl}$ uptake. The result clearly suggests that $p\left(\mathrm{Cl}_{2}\right)$ does not contribute under these oxygen-rich conditions to the $\mathrm{Cl}$ uptake as the $\mathrm{Cl}$ :Ce ratio scatters around the same $\sim 0.096$ value. When $\mathrm{Cl}_{2}$ is completely switched off, no effect is observed, indicating that the $\mathrm{Cl}$ uptake from $5 \mathrm{~cm}^{3} \mathrm{~min}^{-1} \mathrm{Cl}_{2}$ flow was within the error bar of the measurement. This is at odds to the inhibition experiment described in the next paragraph. 
The rate of chlorine production over $\mathrm{CeO}_{2}-\mathrm{A}$ was measured upon progressively increasing the amount of $\mathrm{Cl}_{2}$ added to the feed mixture of $\mathrm{O}_{2}: \mathrm{HCl}=9$. A negative near linear correlation was found between the reaction rate and the inlet concentration of $\mathrm{Cl}_{2}$ added (Figure 5), indicating that molecular chlorine has a moderately strong inhibiting effect on the reactivity of the catalyst. In view of the PGAA data, this result cannot be rationalized on the basis of an increase of the surface $\mathrm{Cl}$ coverage in measurable quantities.

\section{EPR experiments of $\mathrm{O}_{2}$ adsorption}

Ceria, owing to its character to reversibly exchange lattice oxygen, plays an important role in many oxidative catalytic processes. Thus, it is expected that surface chlorination influences its reducibility. Oxygen vacancies formed on the surface of the catalyst can be quantitatively investigated by means of EPR spectroscopy. ${ }^{17,18,19,20} \mathrm{O}_{2}$ can be used as probe molecule for this purpose, because it binds to defects forming paramagnetic superoxide species, $\mathrm{O}_{2}^{-}$.

EPR spectra of fresh $\left(\mathrm{CeO}_{2}-\mathrm{A}\right)$ and chlorinated $\left(\mathrm{CeO}_{2}-\mathrm{D}\right)$ ceria were collected, the samples being subjected to mildly reducing treatments in vacuum $\left(\sim 10^{-5} \mathrm{mbar}\right)$ at different temperatures within $523-723 \mathrm{~K}$ followed by $\mathrm{O}_{2}$ adsorption at $298 \mathrm{~K}$, in order to form the EPR-active superoxide species. By comparing the spectra of the samples before and after chlorination, significant changes in the signals' shape and intensities were observed (Figure 6). EPR spectra of $\mathrm{CeO}_{2}$-A show a signal with quasi-axial line shape (Figure 6A), which is assigned to superoxides species (O1-type $)^{21}$ having equivalent $\mathrm{O}$ atoms and lying parallel to the surface. ${ }^{20}$ The corresponding g values are listed in Table ESI1 and agree well with the values reported in the literature. The EPR spectra of $\mathrm{CeO}_{2}-\mathrm{D}$ exhibit a signal with a rhombic shaped (Figure $6 \mathrm{~B}$ ), with $\mathrm{g}_{\mathrm{x}}$ shifted slightly towards higher values, which is again consistent with data found in the literature for a chlorinated sample. ${ }^{22}$ As opposed to $g_{x}$, the $g_{y}$ and $g_{z}$ values are essentially unaffected upon chlorination. Note that according to the so-called 
ionic model of the $\mathrm{M}^{\mathrm{n}+}-\mathrm{O}_{2}{ }^{-}$radicals, the $\mathrm{g}_{\mathrm{x}}$ tensor value must lie very close to the free electron $\mathrm{g}$ value $\left(\mathrm{g}_{\mathrm{e}}=2.0023\right)$, bearing in mind that the $\mathrm{x}$ axis is considered to be normal to the O-O$\mathrm{M}^{\mathrm{n}+}$ plane. ${ }^{23}$ Thus, a plausible interpretation of the $\mathrm{g}_{\mathrm{x}}$ shift is a somewhat higher degree of covalent character in the $\mathrm{Ce}^{4+}-\mathrm{O}_{2}{ }^{-}$bond induced by the substitution of lattice $\mathrm{O}$ atoms by $\mathrm{Cl}^{24}$

The amount of paramagnetic species produced on the samples was obtained from the double integration of the signals. Figure $6 \mathrm{C}$ shows that a maximum amount of superoxide species was formed over $\mathrm{CeO}_{2}-\mathrm{A}$ as a function of the reduction temperature and that outgassing at higher temperature gave rise to a decline of the superoxide intensity. Intuitively, one would expect even more reduced sites at higher temperature, and hence the formation of more superoxide species. However, at high temperatures oxygen vacancies can diffuse into the bulk, since this is energetically more favored compared to being trapped at the surface, ${ }^{25}$ and, thus, less superoxide could form. Additionally, at higher $T$ vacancies may cluster and upon $\mathrm{O}_{2}$ adsorption these can be filled by $\mathrm{O}_{2}$ dissociation, thus impeding the formation of superoxides. The chlorinated sample generally produced fewer superoxide species, and exhibited a much smaller effect on temperature changes. No maximum was found in this case, and the highest superoxide signal intensity was observed after pre-treatment at $723 \mathrm{~K}$. Hence, we can conclude that chlorination inhibits facile vacancy formation and, thus, lowers the propensity of ceria to activate oxygen.

\section{Discussion}

A relatively simple catalytic reaction, $\mathrm{HCl}$ oxidation over $\mathrm{CeO}_{2}$, has been investigated, and we focused our attention 1) on the chemical changes occurring on the surface and in the near-surface region of ceria, and 2) to quantify the surface species under multiple steady states; with the hope to correlate both 1) and 2) with reactivity. PGAA experiments following chlorination and dechlorination kinetics have clearly indicated the detrimental role of 
subsurface/bulk chlorination on the reactivity. It is likely that this has its origin in the high surface $\mathrm{Cl}$ coverage necessary for facilitating $\mathrm{Cl}$ diffusion into the bulk and concomitant removal of lattice $\mathrm{O}$ in the formation of water. Losing lattice $\mathrm{O} /$ vacancy dynamics by extended near-surface chlorination hinders oxygen activation. EPR experiments have shown that the number of surface $\mathrm{O}$ vacancies enabling the formation of superoxide species upon $\mathrm{O}_{2}$ adsorption drastically diminishes for the chlorinated sample. This implies that oxygen activation during $\mathrm{HCl}$ oxidation is a critical elementary step when the $\mathrm{Cl}$ surface coverage is high. Our recent characterization of the acid/base properties of ceria after $\mathrm{HCl}$ oxidation indicated that sites with basic character were essentially eliminated from the surface of chlorinated $\mathrm{CeO}_{2}{ }^{12}$ That is, most of the lattice $\mathrm{O}$ sites have been exchanged by $\mathrm{Cl}$ and the $\mathrm{OH}$ groups formed are rather acidic. Notice, $\mathrm{HCl}$ activation is thought to require basic sites to abstract $\mathrm{H}$. Therefore, it is not surprising to see that $p\left(\mathrm{O}_{2}\right)$ has a clear negative effect on the $\mathrm{Cl}$ uptake and a concomitant positive influence on reactivity. Higher $\mathrm{O}_{2}$ over-stoichiometry will liberate chlorinated sites by dissociative $\mathrm{O}_{2}$ adsorption to enable $\mathrm{HCl}$ dissociative adsorption. This gives rise to less site blocking by $\mathrm{Cl}$ and a higher population of $\mathrm{OH}$ groups.

Remarkably, $\mathrm{Cl}$ and $\mathrm{OH}$ population changes were, as a rule, complementary upon variation by the reaction conditions $\left(p\left(\mathrm{O}_{2}\right), p(\mathrm{HCl})\right.$, and T). Higher temperature and $p\left(\mathrm{O}_{2}\right)$ as well as lower $p(\mathrm{HCl})$ decreased $\mathrm{Cl}$ and increased $\mathrm{OH}$ coverage. This indicates that the major role of temperature is to diminish site blocking by $\mathrm{Cl}$. On the contrary, increasing $p(\mathrm{HCl})$ gives rise to higher $\mathrm{Cl}$ coverage and parallel increase of reactivity, though only in the range where no subsurface and bulk chlorination sets in. This influence of $\mathrm{HCl}$ partial pressure points to a significantly more complex role of the coverage with $\mathrm{Cl}$ containing species, which may be divided into two contributions: one major part being detrimental, as discussed, most probably by site blocking, whereas a small but certain part is "reactive". Surface sites binding $\mathrm{Cl}$ after dissociation less strongly can contribute to the latter group. Further, during $\mathrm{HCl}$ 
oxidation lateral interactions at high coverages may give rise to lower heat of adsorption of reactants that can accelerate the reaction. Such lateral interactions for adsorbed $\mathrm{HCl}$ may be operative in increasing reactivity at high $\mathrm{HCl}$ partial pressures.

Molecular chlorine was predicted to have a weak effect on surface chlorination. ${ }^{9}$ Only at high $p\left(\mathrm{Cl}_{2}\right)$ and very low $p\left(\mathrm{O}_{2}\right)$ surface $\mathrm{Cl}$ will stabilize in a lattice $\mathrm{O}$ vacancy or at the cus $\mathrm{Ce}^{4+}$ site. This is in perfect agreement with our PGAA observation, as extra $\mathrm{Cl}_{2}$ product cofeeding in the range investigated (up to $5 \mathrm{~cm}^{3} \mathrm{STP} \min ^{-1} \mathrm{Cl}_{2}$ next to $16.6 \mathrm{~cm}^{3} \mathrm{STP} \mathrm{min}^{-1} \mathrm{HCl}$ ) was not able to induce any increase of the $\mathrm{Cl}$ :Ce ratio. On the other hand, $\mathrm{Cl}_{2}$ gives rise to strong inhibition, as the same amount $\left(5 \mathrm{~cm}^{3} \mathrm{STP} \mathrm{min}^{-1}\right)$ of $\mathrm{Cl}_{2}$ reduced reactivity by $\sim 45 \%$. The way products can inhibit reaction is most often related to site blocking by adsorption. Further, the heat of adsorption of reactants may be modulated by other adsorbates (promoters and poisons), but interaction of $\mathrm{Cl}_{2}$ with ceria is weak and dissociation leads to surface $\mathrm{Cl}$, hence inhibition by the modification of the surface electronic structure is not likely. Since $\mathrm{Cl}_{2}$ inhibition is not persistent and turning off $\mathrm{Cl}_{2}$ product feeding restores reactivity quickly, complex restructuring phenomena are also not likely, and rather inhibition is expected to occur by competitive adsorption and site blocking. As, however, this was not observable within the uncertainty $(\sim 2 \%)$ of the experiment, one can conclude that the number of sites critically involved in the reaction should be very small (also in the range of few percent). Consequently, most surface sites probed in the in situ spectroscopic (FTIR and PGAA) experiments correspond to either sites holding spectators, or function only as buffer. The reactivity of most surface sites is thus likely negligibly low and only very few high energy sites can effectively contribute in the observed catalytic turnover. Nevertheless, nearby sites temporarily storing surface species may supply adsorbates to the high energy site, which may effectively catalyze recombination and desorption of products. Then, the convincing correlations found in the in situ FTIR and PGAA experiments (Figures 3 and 4) do not 
correspond to the relevant active surface sites, but rather describe the equilibration of the major non-reactive surface units with the reactants and the adjustment to the reaction conditions. Although in situ or operando studies deserve the attention of the catalysis community and usually represent a step up from standard works with reactivity and ex situ characterization, the experiments described here suggest that one should at least exercise some caution when deriving strong conclusions from a limited set of in situ (operando) experiments. Investigating a larger set of variables may override frivolously derived correlations and conclusions.

\section{Conclusions}

Ceria is a catalyst with high industrialization potential for $\mathrm{HCl}$ oxidation. We have investigated various aspects of this reaction system. Subsurface and bulk chlorination gives rise to deactivation, and we studied the kinetics of this as well as the inverse dechlorination process. In line with the negative role of chlorination, the rate of chlorination is higher with lower oxygen over-stoichiometry (but is independent of the pre-chlorination degree), whereas dechlorination is facilitated at high oxygen partial pressures. At the limit, $\mathrm{CeCl}_{3}$ transforms to $\mathrm{CeO}_{2}$ under reaction condition.

The surface coverage of the two most abundant species $\mathrm{Cl}$ and $\mathrm{OH}$ was followed under multiple steady states as a function of $p\left(\mathrm{O}_{2}\right), p(\mathrm{HCl}), p\left(\mathrm{Cl}_{2}\right)$, and $T$ without the influence of subsurface chlorination. Oxygen and temperature removes some surface $\mathrm{Cl}$ and increases the $\mathrm{OH}$ population with concomitant reactivity enhancement. Hence, in these experiments $\mathrm{OH}$ positively and $\mathrm{Cl}$ negatively correlates with the reactivity. On the other hand, in oxygen-rich feeds higher $p(\mathrm{HCl})$ gives rise to increased activity, but also to higher coverage of $\mathrm{Cl}$ containing species (and less $\mathrm{OH}$ ), and, therefore, here an opposite trend is observed. Lastly, $\mathrm{Cl}_{2}$ strongly inhibits the reaction but no measureable increase of $\mathrm{Cl}$ uptake 
was found. This latter result leads us to the conclusion that essentially all of the surface probed in the in situ experiments correspond to the main part of the surface bearing little relevance to the reactivity. This complex set of experiments highlights the role to investigate a broad field of reaction parameters before deriving strong but artificial surface-reactivity correlations.

\section{Acknowledgement}

The authors acknowledge support from BMBF Project 033R018A, Bayer MaterialScience, ETH Zurich, the EU FP7 NMI3 Access Programme, the NAP VENEUS grant (OMFB00184/2006) and the cooperation project between the Fritz-Haber Institute and the former Institute of Isotopes funded by the MPG. Bayer MaterialScience is acknowledged for permission to publish this article. Núria López is thanked for valuable discussions. 


\section{Figures}
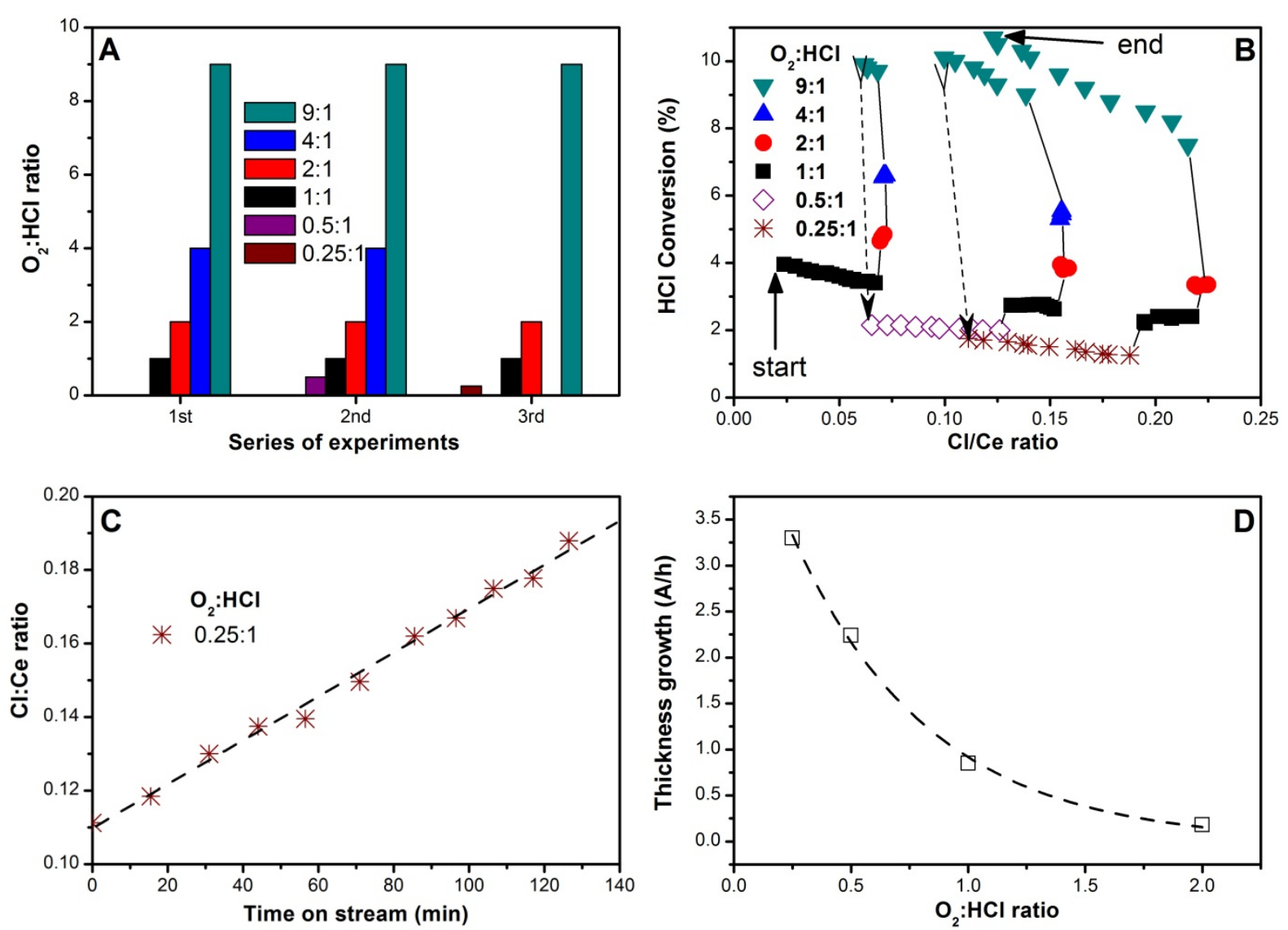

Figure 1: Series of chlorination/dechlorination experiments over $\mathrm{CeO}_{2}-\mathrm{R}$ at $703 \mathrm{~K}$ by in situ PGAA. A) Map of experiments with three series. Various $\mathrm{O}_{2}: \mathrm{HCl}$ feed ratios $(10 \% \mathrm{HCl}, 2.5-$ $90 \% \mathrm{O}_{2}$ balanced in $\mathrm{N}_{2}$ ) were probed. Measurements were performed from left to right consecutively, however for different time periods. B) Evolution of $\mathrm{HCl}$ conversion and $\mathrm{Cl}$ uptake (as $\mathrm{Cl}: \mathrm{Ce}$ ) in the experiments. The first data point is at $4 \%$ conversion. The lines guide the eyes to follow the order of experiments. C) An example of $\mathrm{Cl}$ uptake over time-on-stream with a feed of $\mathrm{O}_{2}: \mathrm{HCl}=0.25: 1$. D) Thickness growth of chlorinated shell as a function of the feed oxygen content. The rate of $\mathrm{Cl}$ uptake was evaluated in a simple geometric model (with particle radius of $82 \mathrm{~nm}$ ) and assuming a homogeneous growth of the chlorinated surface shell towards the particle core. The thickness growth describes the speed of the chlorinated front moving toward the core of the ceria particle. 

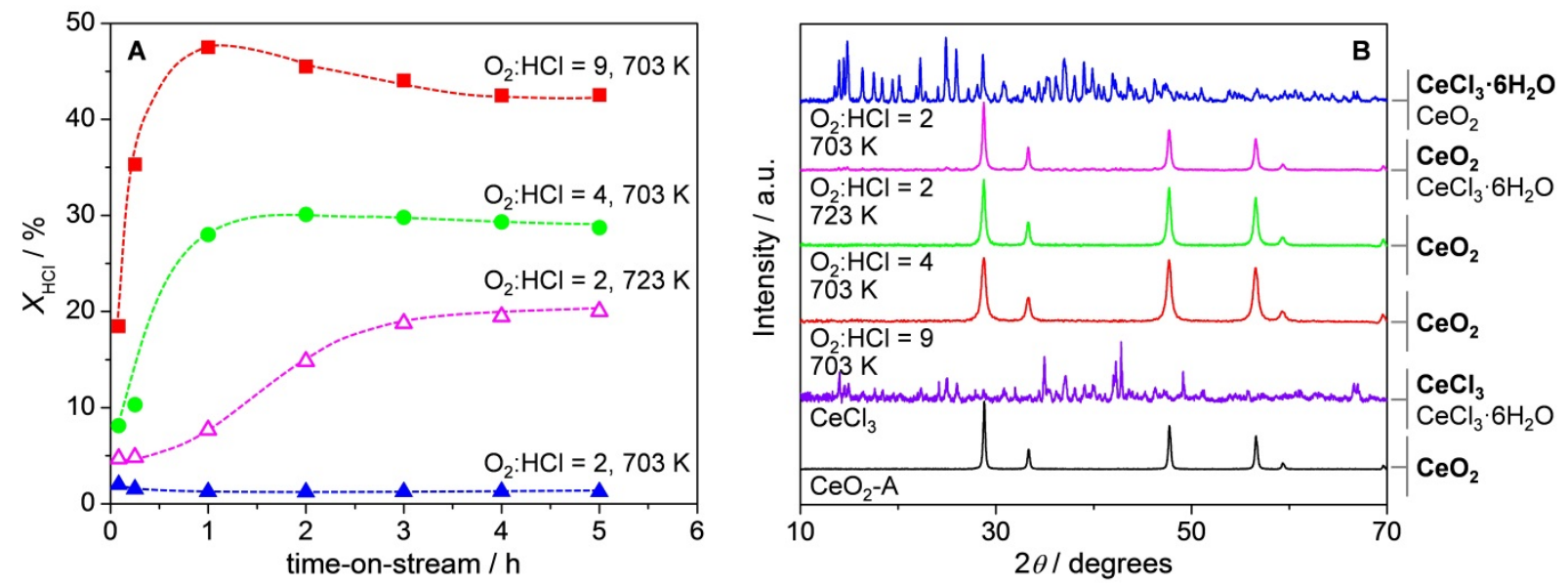

Figure 2: Rejuvenation of the $\mathrm{CeO}_{2}$ phase from $\mathrm{CeCl}_{3}$ under Deacon conditions. (A) $\mathrm{HCl}$ conversion versus time-on-stream over $\mathrm{CeCl}_{3}$ at various $\mathrm{O}_{2}: \mathrm{HCl}$ ratios and temperatures. Other conditions: 10 vol.\% $\mathrm{HCl}$ and 20-90 vol.\% $\mathrm{O}_{2}$ balanced in $\mathrm{N}_{2}$, space time $=11.2 \mathrm{~g} \mathrm{~h} \mathrm{~mol}^{-1}$, total volumetric flow $=166 \mathrm{~cm}^{3} \mathrm{STP} \mathrm{min}^{-1}$, and 1 bar. (B) XRD patterns of fresh $\mathrm{CeO}_{2}-\mathrm{A}$, fresh $\mathrm{CeCl}_{3}$, and $\mathrm{CeCl}_{3}$ samples resulted from the catalytic tests. The right panel lists the crystalline phases present in the samples, with the predominant phase in bold: $\mathrm{CeO}_{2}$ (JCPDS 73-6328), $\mathrm{CeCl}_{3}$ (JCPDS 77-0154), $\mathrm{CeCl}_{3} \cdot 6 \mathrm{H}_{2} \mathrm{O}$ (JCPDS 01-0149). 

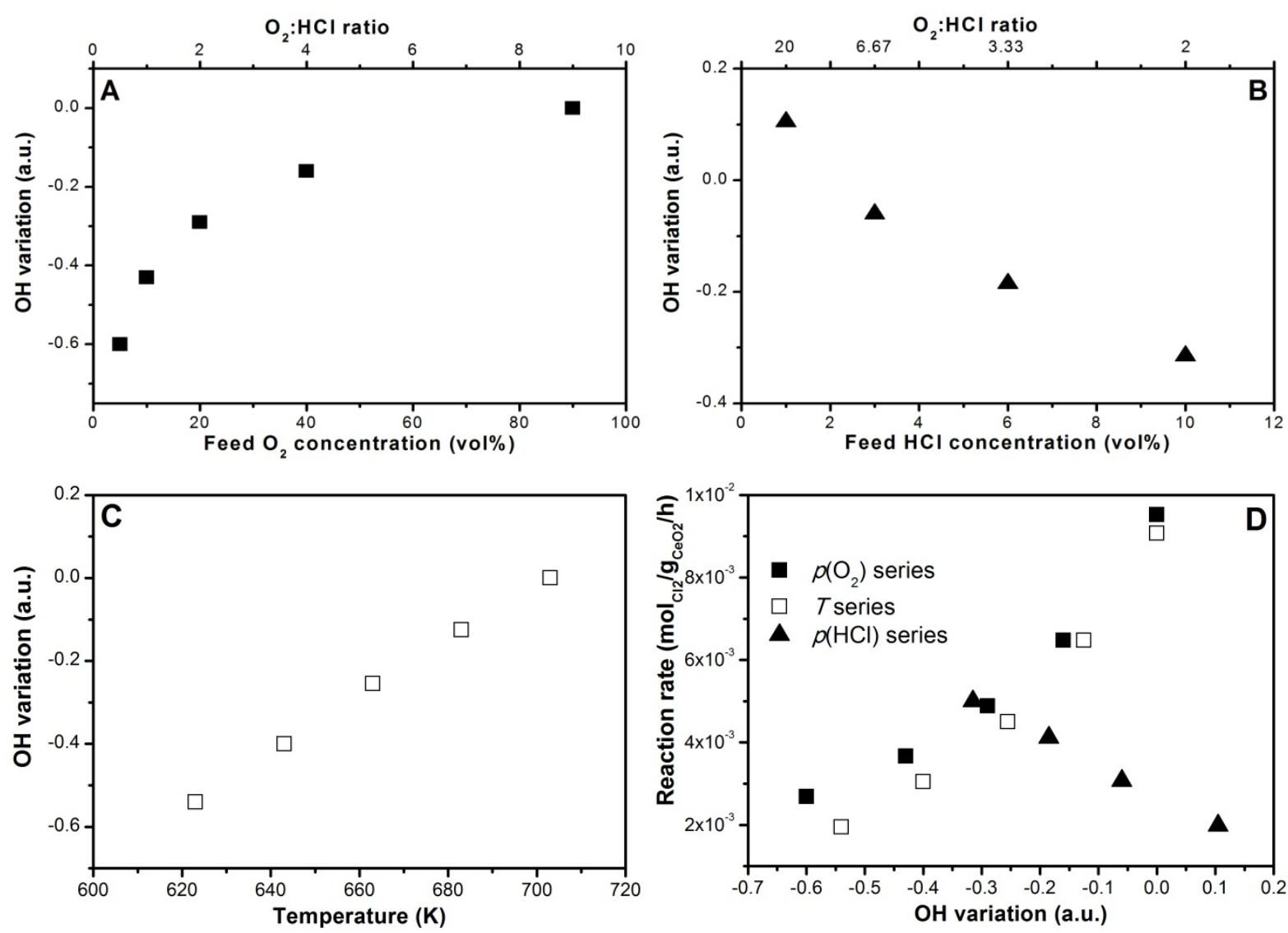

Figure 3: Evolution of the intensity of the mono-coordinated $\mathrm{OH}$ band at $3730 \mathrm{~cm}^{-1}$ as a function of $(\mathrm{A}) p\left(\mathrm{O}_{2}\right),(\mathrm{B}) p(\mathrm{HCl}),(\mathrm{C})$ temperature as measured by in situ FTIR on $\mathrm{CeO}_{2}-\mathrm{A}$. The absorbance spectra were fitted and the area variation referenced to the condition $\mathrm{O}_{2}: \mathrm{HCl}$ $=9: 1$ at $703 \mathrm{~K}$ was plotted. D) Reaction rate, measured in parallel by iodometric titration, versus the intensity of the $\mathrm{OH}$ band under different conditions. 

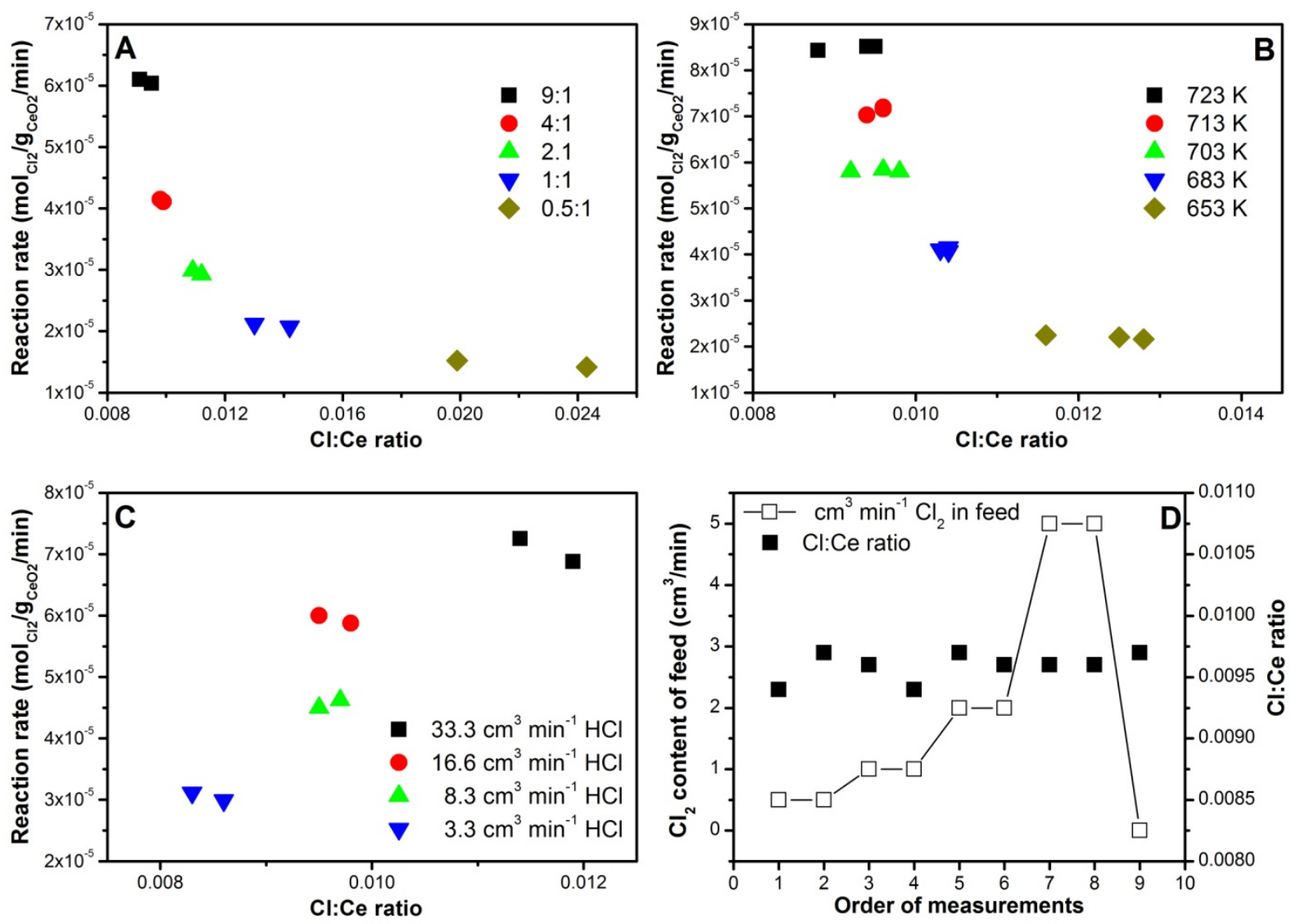

Figure 4: In situ PGAA experiments on $\mathrm{CeO}_{2}-\mathrm{R}$ showing the reaction rate evolution as a function of $\mathrm{Cl}$ :Ce ratio under various conditions. In (A) the feed oxygen content (at $703 \mathrm{~K}$ ), in (B) the temperature (at $\mathrm{O}_{2}: \mathrm{HCl}=9: 1$ ) and in $(\mathrm{C})$ the feed $\mathrm{HCl}$ content (at $703 \mathrm{~K}$ ) was varied. (D) $\mathrm{Cl}$ :Ce ratio as a function of various amounts of $\mathrm{Cl}_{2}$ co-dosed to a 9:1 feed at $703 \mathrm{~K}$. In ESI, corresponding $p\left(\mathrm{O}_{2}\right)$ and $T$ dependences on $\mathrm{CeO}_{2}$-A are shown to be identical to those given here. Table 1 suggests that with $\mathrm{CeO}_{2}-\mathrm{R}$ and $\mathrm{CeO}_{2}-\mathrm{A}$ both reactivity and $\mathrm{Cl}$ uptake are similar when normalized to the corresponding BET surface area. 


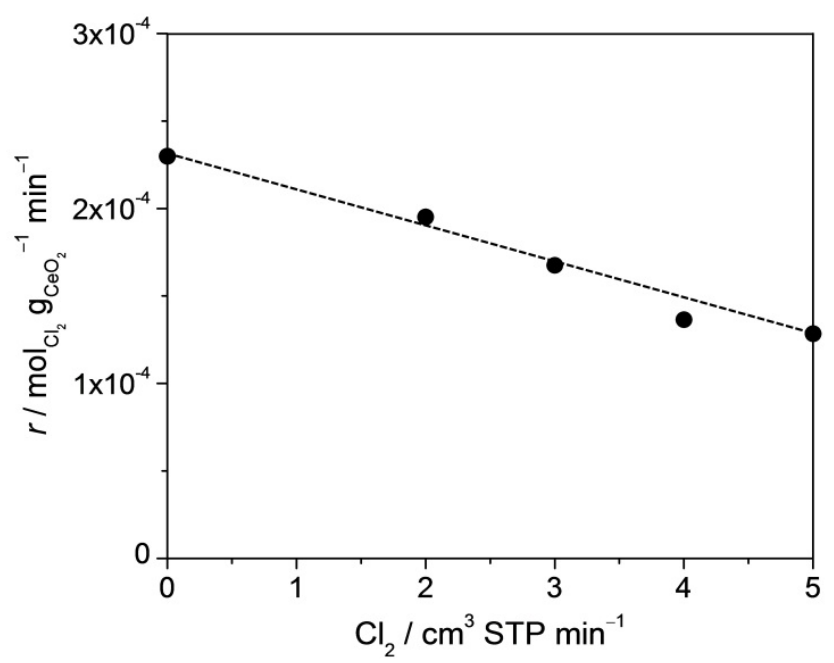

Figure 5: Influence of $\mathrm{Cl}_{2}$ co-feeding on the rate of $\mathrm{HCl}$ oxidation over $\mathrm{CeO}_{2}-\mathrm{A}$. Conditions: 10 vol. $\% \mathrm{HCl}$ and 90 vol. $\% \mathrm{O}_{2}, 703 \mathrm{~K}$, space time $=5.6 \mathrm{~g} \mathrm{~h} \mathrm{~mol}^{-1}$, total volumetric flow $=166 \mathrm{~cm}^{3} \mathrm{STP} \min ^{-1}, 1 \mathrm{bar}$, and dwelling time under each condition $=1.5 \mathrm{~h}$. 

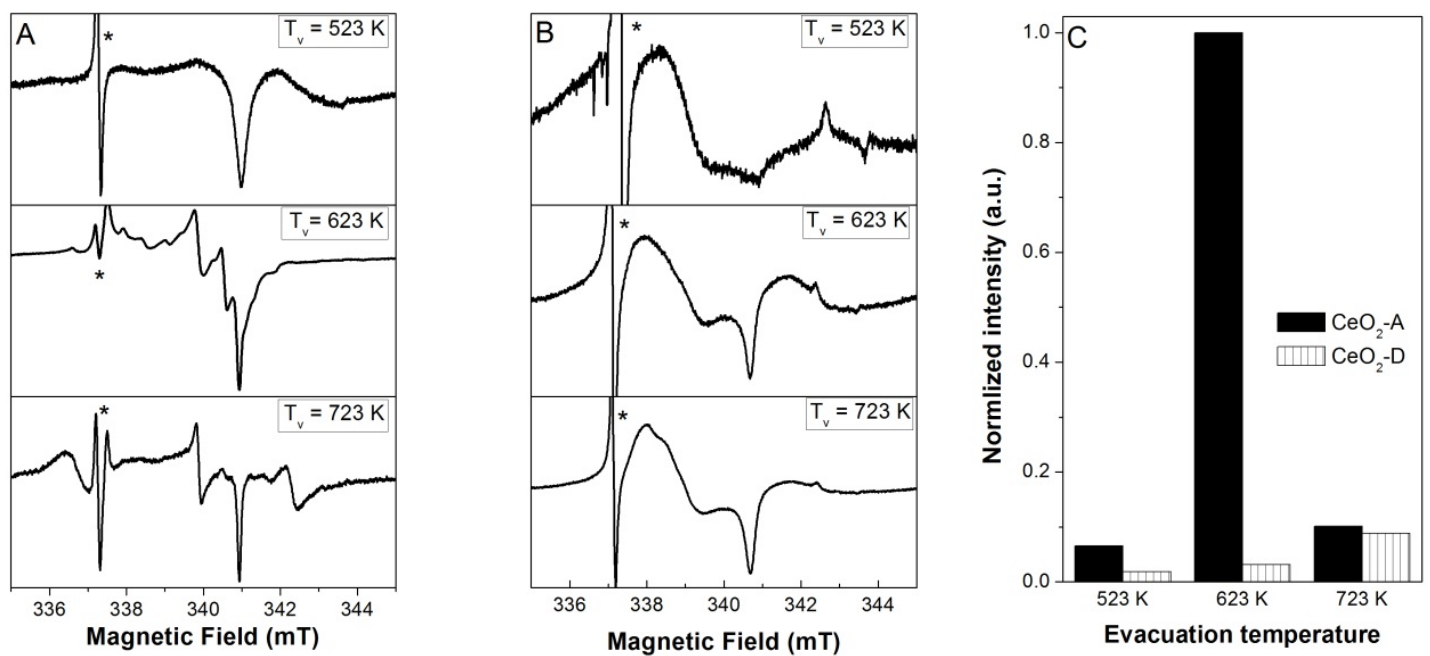

Figure 6: EPR signals of superoxide species produced by $\mathrm{O}_{2}$ adsorbed at RT on pre-reduced samples (A) $\mathrm{CeO}_{2}-\mathrm{A}$ and (B) $\mathrm{CeO}_{2}-\mathrm{D}$. Signal marked with * is due to highly EPR-active $\mathrm{Mn}^{2+}$ impurities in the ceria. (C) The amount of superoxide was quantified by double integration of signals assigned to superoxides. 


\section{References}

${ }^{1}$ M. M. Schubert, M. J. Kahlich, H. A. Gasteiger, R. J. Behm, J. Power Sources 84, 1999, 175.

${ }^{2}$ L. J. Burcham, L. E. Briand, I. E. Wachs, Langmuir 17, 2001, 6174.

${ }^{3}$ F. C. Meunier, Catal. Today 155, 2010, 164.

${ }^{4}$ T. Hibi, H. Abekawa, K. Seki, T. Suzuki, T. Suzuta, K. Iwanaga, T. Oizumi, EP936184, 1999.

${ }^{5}$ A. Wolf, L. Mleczko, O. F. Schlüter, S. Schubert, EP2026905, 2006.

${ }^{6}$ J. Pérez-Ramírez, C. Mondelli, T. Schmidt, O. F. -K. Schluter, A. Wolf, L. Mleczko, T. Dreier, Energy Environ. Sci. 4, 2011, 4786.

${ }^{7}$ H. Over, J. Phys. Chem. C 116, 2012, 6779.

${ }^{8}$ D. Teschner, R. Farra, L.-D. Yao, R. Schlögl, H. Soerijanto, R. Schomaecker, T. Schmidt, L. Szentmiklósi, A.P. Amrute, C. Mondelli, J. Pérez-Ramírez, G. Novell-Leruth, N. López, J. Catal. 285, 2012, 273.

${ }^{9}$ A. P. Amrute, C. Mondelli, M. Moser, G. Novell-Leruth, N. Lopez, D. Rosenthal, R. Farra, M. E. Schuster, D. Teschner, T. Schmidt, J. Pérez-Ramírez, J. Catal. 286, 2012, 287.

${ }^{10}$ Zs. Révay, T. Belgya, L. Szentmiklósi, Z. Kis, A. Wootsch, D. Teschner, M. Swoboda, R. Schlögl, J. Borsodi, R. Zepernick, Anal. Chem. 80, 2008, 6066.

${ }^{11}$ A.P. Amrute, C. Mondelli, J. Pérez-Ramírez, Catal. Sci. Tech. 2, 2012, 2057.

${ }^{12}$ R. Farra, M. E. Schuster, S. Wrabetz, E. Stotz, N. G. Hamilton, A. P. Amrute, J. PérezRamírez, N. López, D. Teschner, Phys. Chem. Chem. Phys., submitted

${ }^{13}$ X. T. Gao, S. R. Bare, J. L. G. Fierro, M. A. Banares, I. E. Wachs, J. Phys. Chem. B 102, $1998,5653$.

${ }^{14}$ L. Burcham, G. Deo, X. Gao, I. Wachs, Top. Catal. 11-12, 2000, 85.

${ }^{15}$ G. Le Bourdon, F. Adar, M. Moreau, S. Morel, J. Reffner, A. S. Mamede, C. Dujardin, E. Payen, Phys. Chem. Chem. Phys. 5, 2003, 4441.

${ }^{16}$ A. Badri, C. Binet, J.-C. Lavalley, Faraday Trans. 92, 1996, 4669.

${ }^{17}$ M. Gideoni, M. Steinberg, J. Solid State Chem. 4, 1972, 370.

${ }^{18}$ A. Aboukais, E. A. Zhilinskaya, J.-F. Lamonier, I. N. Filimonov, Colloids Surf., A 260, 2005, 199. 
${ }^{19}$ M. Che, J. F. J. Kibblewhite, A. J. Tench, M. Dufaux, C. Naccache, J. Chem. Soc., Faraday Trans. 1 69, 1973, 857.

${ }^{20}$ A. Martínez-Arias, J. C. Conesa, J. Soria, Res. Chem. Intermed. 33, 2007, 775.

${ }^{21}$ J. Soria, A. Martínez-Arias, J. C. Conesa, Faraday Trans. 91, 1995, 1669.

22 J. Soria, J. C. Conesa, A. Martínez-Arias, Colloids Surf., A 158, 1999, 67.

${ }^{23}$ M. Anpo, M. Che, B. Fubini, E. Garrone, E. Giamello, M. Paganini, Top. Catal. 8, 1999, 189.

${ }^{24}$ J. Soria, A. Martínez-Arias, J. M. Coronado, J. C. Conesa, Top. Catal. 11-12, 2000, 205.

${ }^{25}$ M. V. Ganduglia-Pirovano, J. L. F. Da Silva, J. Sauer, Phys. Rev. Lett. 102, 2009, 026101. 